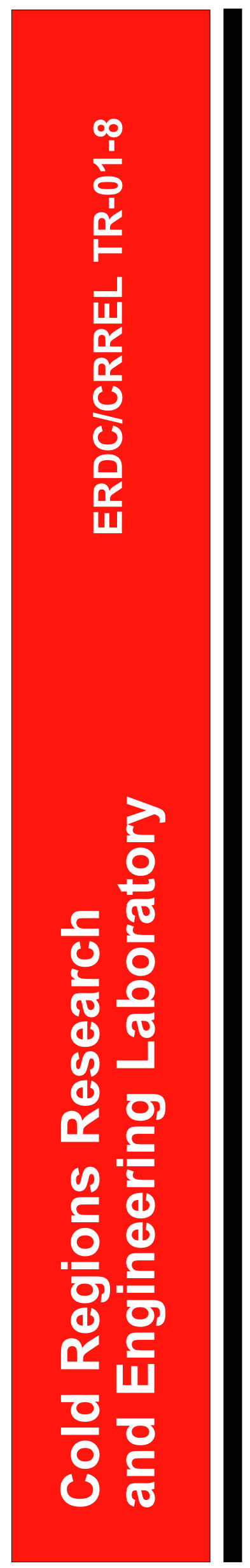

Influence of Wheel Load Shape on Vertical Stress Reaching Subgrade through an Aggregate Layer

Karen S. Henry

March 2001 
Abstract:The U.S. Army design procedure to stabilize low-bearing-capacity soil with geotextiles is based on the assumption that the applied surface load (the wheel load) is in the shape of a circle. The maximum vertical stress that reaches the subgrade through overlying aggregate is then estimated on the basis of the assumption that the aggregate is an elastic, homogeneous, isotropic half-space and, therefore, that the stress distribution can be estimated by using the Boussinesq method. To study the extent to which the shape of the applied load influences the stress that reaches the subgrade through the aggregate layer, the maximum vertical stress at depth predicted by the Boussinesq method was computed and compared for circular and rectangular loads. A comparison of the maximum vertical stress beneath circular and rectangular loads as a function of depth indicated that the differences were insufficient to warrant a change in the design procedure for rectangular load geometries that have length/width ratios of 3 or less, and, furthermore, that assuming that the load is circular is conservative. For length/width ratios of 3 or less, the maximum vertical stress applied by a rectangle is at least $85 \%$ of that applied by a circle.

How to get copies of CRREL technical publications:

Department of Defense personnel and contractors may order reports through the Defense Technical Information Center:

DTIC-BR SUITE 0944

8725 JOHN J KINGMAN RD

FT BELVOIR VA 22060-6218

Telephone (800) 225-3842

E-mail help@dtic.mil msorders@dtic.mil

WWW http://www.dtic.mil/

All others may order reports through the National Technical Information Service:

NTIS

5285 PORT ROYAL RD

SPRINGFIELD VA 22161

Telephone (703) 487-4650

(703) 487-4639 (TDD for the hearing-impaired)

E-mail_orders@ntis.fedworld.gov

WWW http://www.ntis.gov/index.html

A complete list of all CRREL technical publications is available from USACRREL (CEERD-IM-HL)

72 LYME RD

HANOVER NH 03755-1290

Telephone (603) 646-4338

E-mail erhoff@crrel.usace.army.mil

For information on all aspects of the Cold Regions Research and Engineering Laboratory, visit our World Wide Web site: 


\section{Technical Report ERDC/CRREL TR-01-8}

\section{Influence of Wheel Load Shape on Vertical Stress Reaching Subgrade through an Aggregate Layer}

Karen S. Henry 


\section{PREFACE}

This report was prepared by Karen S. Henry, Ph.D., P.E., Research Civil Engineer, Civil Engineering Research Division, U.S. Army Engineer Research and Development Center (ERDC), Cold Regions Research and Engineering Laboratory (CRREL), Hanover, New Hampshire.

The work presented in this report was funded by U.S. Army Corps of Engineers work unit AT42-TO-007, Cold Regions Theater of Operations Engineering, under the work unit entitled Use of Geosynthetics to Rapidly Reinforce Thawing Soils. The author thanks George Blaisdell, Research Civil Engineer, and Dr. Paul Richmond, Mechanical Engineer, both of CRREL, for technical review of this report.

The contents of this report are not to be used for advertising or promotional purposes. Citation of brand names does not constitute an official endorsement or approval of the use of such commercial products. 


\title{
Influence of Wheel Load Shape on Vertical Stress Reaching Subgrade through an Aggregate Layer
}

\author{
KAREN S. HENRY
}

\section{INTRODUCTION}

The U.S. Army design procedure to stabilize lowbearing-capacity soil with geotextiles for traffic involves placing aggregate on geotextiles (U.S. Army and U.S. Air Force 1995). It is based on the assumption that the applied surface load (the wheel load) is in the shape of a circle (e.g., Henry 1999). The vertical stress that reaches the subgrade from the applied wheel load is then estimated on the basis of the assumption that the aggregate is an elastic, homogeneous, isotropic half-space and, therefore, that the stress distribution can be estimated by using the Boussinesq method (e.g., Newmark 1942). The stress distribution determined by the Boussinesq approach is assumed to be accurate for the prediction of stresses distributed through compacted crushed rock and through asphalt (e.g., Barenberg et al. 1975, Yoder and Witzcak 1975). However, it is not clear that a circular area accurately predicts stress for non-circular wheel load shapes. For example, a common configuration of dual wheels on a single axle has been modeled as a rectangular area (e.g., Giroud and Noiray 1981). To quantify the extent to which the shape of the applied load influences the stress that reaches the subgrade through the aggregate layer, I analyzed the influence of the shape of the wheel load on the maximum vertical stress at depth predicted by the Boussinesq method.

Since it is the maximum vertical stress (i.e., the stress beneath the center of the loaded area) that is used in the design procedure, I examined the influence of the shape of the applied load on the maximum vertical stress predicted by the Boussinesq approach. If significant differences in the maximum vertical stresses below uniformly loaded rectangles and circles were found, then the wheel load shape (i.e., rectangle or circle) should be accounted for in the design proce- dure. A comparison of the maximum vertical stress beneath circular and rectangular loads as a function of depth indicated that the differences were insufficient to warrant a change in the design procedure for rectangular load geometries that have length/width ratios of 3 or less, and, furthermore, that assuming that the load is circular is conservative.

The details of the analysis are presented fully in this report. The techniques may be used to examine other load geometries, including those of tracked vehicles.

\section{STUDY OBJECTIVES}

The goal of this study was to determine whether the shape of the wheel load at the ground surface significantly influences the maximum vertical stress at depth (i.e., that reaches the subgrade) given that the aggregate layer behaves as a linearly elastic material. If a significant difference were to be found between the vertical stresses at depth applied by uniformly loaded circles versus rectangles, then appropriate changes would be made in design guidance developed for vehicles that apply loads that are more accurately modeled as rectangles than circles.

I used the Boussinesq equations to estimate maximum vertical stresses for uniformly loaded circles (Newmark 1942) and rectangles (Newmark 1935). I assumed unit loads and areas, and considered a large range in length-to-width ratios for rectangular wheel loads so that the range of wheel load shapes applied by military vehicles was well represented. The longest rectangle that I studied, at $L=6 \mathrm{~B}$, where $L$ is the contact length and $B$ is the contact width, is too extreme to model wheeled vehicles. The range of normalized 
depths studied represents a range of typical aggregate thicknesses above geotextiles. The technique used can easily be applied to other length/width ratios and other normalized depths.

\section{VERTICAL BOUSSINESQ STRESS BELOW A RECTANGLE}

The vertical stress at depth below the corner of a uniformly loaded rectangle of dimensions $L \times B$ is estimated as (Fig. 1; Newmark 1935)

$$
\begin{gathered}
\sigma_{\mathrm{z}}=\frac{w}{4 \pi}\left[\frac{2 A_{\mathrm{o}} V_{\mathrm{o}}}{V_{\mathrm{o}}^{2}+A_{\mathrm{o}}^{2}} \cdot \frac{V_{\mathrm{o}}^{2}+1}{V_{\mathrm{o}}^{2}}+\right. \\
\left.\left(\tan ^{-1} \frac{2 A_{\mathrm{o}} V_{\mathrm{o}}}{V_{\mathrm{o}}^{2}-A_{\mathrm{o}}^{2}}\right)\right] \text { for } A_{\mathrm{o}}>Z \\
\sigma_{\mathrm{z}}=\frac{w}{4 \pi}\left[\frac{2 A_{\mathrm{o}} V_{\mathrm{o}}}{V_{\mathrm{o}}^{2}+A_{\mathrm{o}}^{2}} \cdot \frac{V_{\mathrm{o}}^{2}+1}{V_{\mathrm{o}}^{2}}+\right. \\
\left.\left(\tan ^{-1} \frac{2 A_{\mathrm{o}} V_{\mathrm{o}}}{V_{\mathrm{o}}^{2}-A_{\mathrm{o}}^{2}}\right)+\pi\right] \text { for } A_{\mathrm{o}}<Z
\end{gathered}
$$

where

$$
\begin{aligned}
w= & \text { applied uniform pressure } \\
Z= & \text { depth below the corner of the rectangle } \\
& \text { for which the vertical stress is desired }
\end{aligned}
$$

$$
\begin{aligned}
& V_{\mathrm{o}}^{2}=\frac{L^{2}+B^{2}+Z^{2}}{Z^{2}} \\
& A_{\mathrm{o}}=\frac{L B}{Z^{2}} .
\end{aligned}
$$

Note that $V_{\mathrm{o}}$ is the ratio of the radius vector from point $Z$ to the corner of the rectangle to the depth of point $Z$. To obtain the stress below the center of the rectangle at depth $Z$, I used superposition and divided the rectangle into four smaller rectangles, such that

and

$$
X=\frac{L}{2}
$$

$$
Y=\frac{B}{2}
$$

and $A$ and $V$ are defined as follows:

$$
A=\frac{X Y}{Z^{2}}
$$

*This form of the equation is not published by Newmark (1935), but it is required to avoid predicting tension (e.g., Bowles 1988).

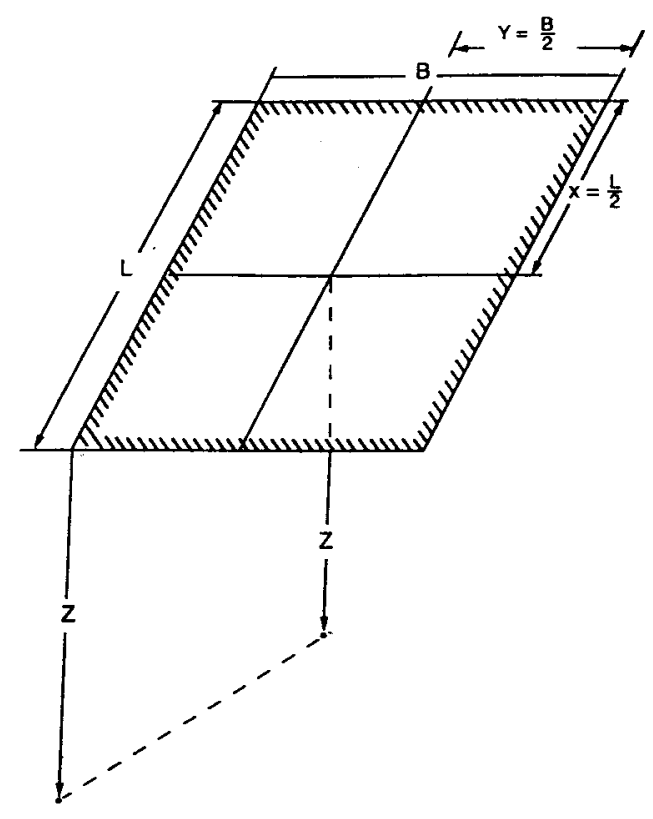

Figure 1. Notation used in the estimation of vertical stress at depth below the corner and center of a uniformly loaded rectangle.

and

$$
V^{2}=\frac{X^{2}+Y^{2}+Z^{2}}{Z^{2}}
$$

Thus $I_{z}$, or the ratio of the vertical stress below the center of a rectangle at depth $Z$ to the stress applied on the rectangle $(L \times B)$ at the surface, is equal to

$$
\begin{gathered}
I_{\mathrm{Z}}=\frac{1}{\pi}\left[\frac{2 A V}{V^{2}+A^{2}} \cdot \frac{V^{2}+1}{V^{2}}+\right. \\
\left.\left(\tan ^{-1} \frac{2 A V}{V^{2}-A^{2}}\right)\right] \text { for } A>Z \\
I_{\mathrm{Z}}=\frac{1}{\pi}\left[\frac{2 A V}{V^{2}+A^{2}} \cdot \frac{V^{2}+1}{V^{2}}+\right. \\
\left.\left(\tan ^{-1} \frac{2 A V}{V^{2}-A^{2}}\right)+\pi\right] \text { for } A<Z .
\end{gathered}
$$

\section{VERTICAL BOUSSINESQ STRESS BELOW A CIRCLE}

The vertical stress at depth $Z$ below the center of a uniformly loaded circle of radius $r$, divided by the applied stress, is estimated as (Fig. 2; Newmark 1942) 


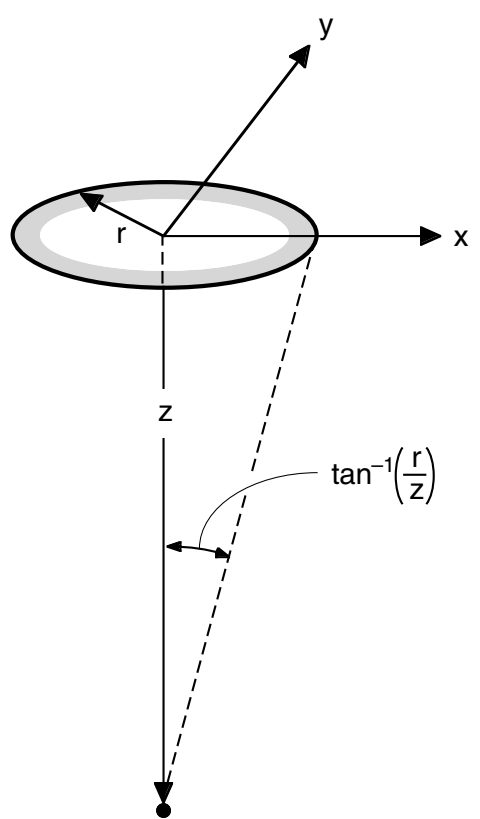

Figure 2. Uniformly loaded circle, showing notation used in the estimation of vertical stress at depth below the center of the circle.

$$
I_{\mathrm{c}}=\left[1-\left[\cos \left[\tan ^{-1}\left(\frac{r}{Z}\right)\right]\right]^{3}\right] .
$$

I used eq 2 and 3 for a unit uniform load and a unit area to compare the stress reduction at various normalized depths estimated by each equation. I varied the length/width ratio of the rectangles from $L=B$ to $L$ $=6 B$ and the normalized depth $Z$ from 0.05 to 2.0 . The range in these parameters reasonably represents the geometry of loads applied by heavy military vehicles. An example of estimating the length-to-width ratio of a wheel load and the values of $V$ and $r$ for a military vehicle follows.

\section{WHEEL LOAD GEOMETRY OF THE M1000 TRAILER}

On-highway trucks typically have $L: B$ ratios of 1.4 and off-highway trucks have L:B ratios of 2.0 (Giroud and Noiray 1981). The M1000 trailer of the Heavy Equipment Transporter System (HETS) (Fig. 3) likely has the highest length/width ratio of a wheel load applied by a U.S. military vehicle. Each axle line of this trailer has eight wheels (two sets of dual wheels on each end) (Fig. 4). If we assume that the soil between the tires aligned on one side of the axle will not fail (e.g., Giroud and Noiray 1981), then the load carried on that side of the axle can be assumed to be distrib- uted over a rectangle (Fig. 4). Based on the information given in Figure 4, the $L: B$ ratio of the uniformly loaded rectangle is approximately 3.9. Note that for a $1-\mathrm{m}$ depth of aggregate, $V$ is equal to 1.16 for this vehicle.

\section{ANALYTICAL STUDY AND RESULTS}

I programmed eq 2 and 3 into a Mathcad 8 programmable worksheet (Mathsoft 1998) and set the area of pressure application equal to one. The results generated include the fraction of the applied vertical stress below the rectangle and the circle, $I_{\text {rect }}$ and $I_{\text {circ }}$, respectively, and the ratio $I_{\text {rect }} / I_{\text {circ }}$. A factor $F$ represents the $L: B$ ratio that was easily changed to examine its influence on results. Appendix A contains a hard copy of the Mathcad worksheet used, tabulated results, and a copy of the Mathcad worksheet for the reader's use.

The ratios of the stress reduction beneath the center of the rectangles to the stress reduction beneath the center of a circle are shown in Figure 5. The maximum vertical stress beneath the circle is always greater than that beneath the rectangles, including the special case of a square. A circle minimizes the ratio of perimeter to area; thus, the circle maximizes the influence of surface pressure at depths below the center. Therefore, applying the assumption that the surface load is circular is conservative compared to assuming other shapes. Furthermore, for length/width ratios of 3 or less, the maximum vertical stress applied by a rectangle is at least $85 \%$ of that applied by a circle. The minimum ratio of the stress beneath a rectangle to a circle for the conditions analyzed occurs at a normalized depth of about 0.6 , and is about 0.65 for a length/ width ratio of 6 . As mentioned earlier, the length/width ratio of 6 is outside the range of load shapes for wheeled U.S. military vehicles.

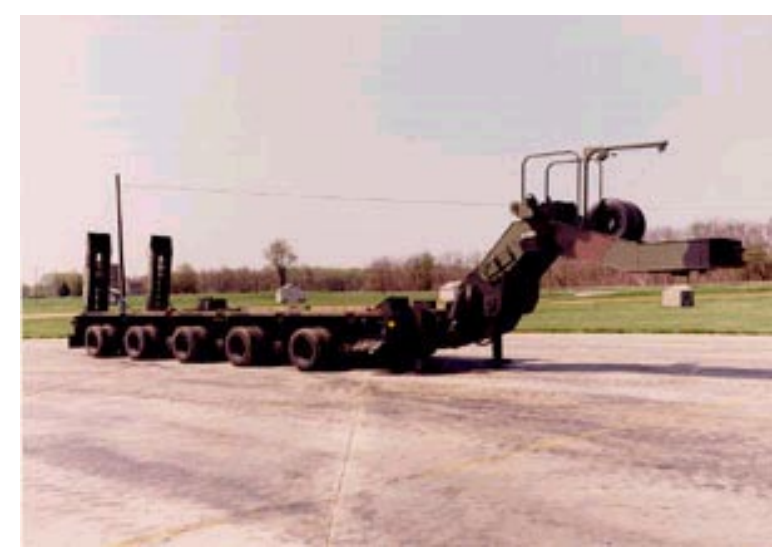

Figure 3. M1000 semi-trailer, downloaded from USA TACOM (1999). 


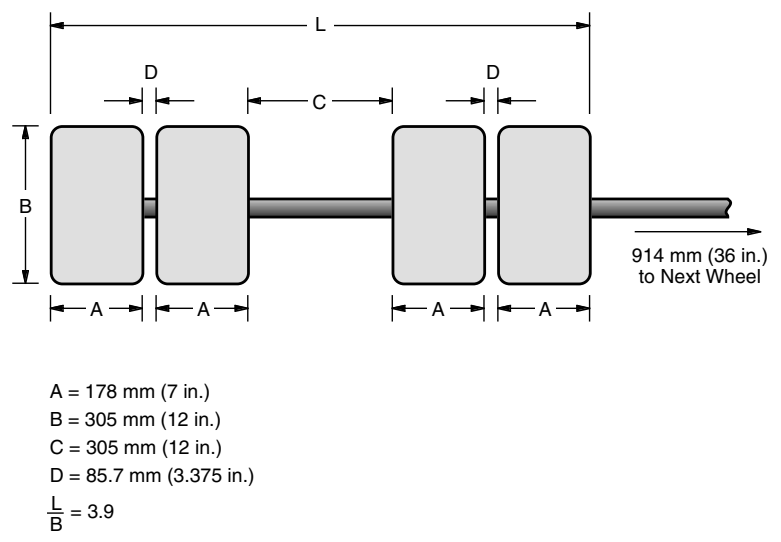

Figure 4. Dimensions of wheels on one end of an axle line of the M1000 trailer.*

\section{DISCUSSION}

Based on the results of the analytical study, there is no compelling reason to assume any wheel load shape other than circular. However, if a vehicle does produce wheel loads than can be approximated as uniformly loaded rectangles with length/width ratios of about 4 or greater, this question should be reconsidered for purposes of modifying design guidance that may be too conservative. In this case, the spreadsheet shown in Appendix A can be used to calculate the stress reduction at depth below the rectangle simply by changing the $F$ value that is input at the top of the spreadsheet. Keep in mind that this approach assumes that the Boussinesq stress distribution provides a reasonable estimate of vertical stress at depth (i.e., the aggregate behaves in a linearly elastic manner and the stress is uniformly applied).

Although not the topic of this study, whether the aggregate that is placed on top of the geotextile behaves as a linearly elastic material is important; related to this is whether the vertical stresses are accurately predicted by the Boussinesq method. The aggregate type and quality significantly influence the stress distribution at depth. McMahon and Yoder (1960) found that pressures in homogeneous, compacted clay soil subgrades followed the Boussinesq pattern, but were up to $18 \%$ higher than those predicted by Boussinesq at shallow depths (e.g., less than the diameter of the loaded area). Further, the presence of compacted crushed limestone base above the clay subgrade reduced the vertical stresses in the subgrade immediately below the interface to values less than those predicted by Boussinesq. Other research indicated that there is a stress concentration in soil layers

*Personal communication with R. Dunbar, Test Director, Yuma Proving Grounds, Yuma, Arizona, 1999. containing significant quantities of sand compared to other aggregates. For example, a 45-kN (10-kip) load was applied at $690 \mathrm{kPa}(100 \mathrm{psi})$ to a subgrade through various aggregates, with the result that the stress reaching the subgrade through a $0.6-\mathrm{m}$ (24-in.) layer of sand was about twice that of the stress through a layer of crushed limestone (Herner 1955). Sowers and Vesic (1962) found that vertical stresses in a 203-mm- (8in.-) thick base consisting of 95\% subangular quartz sand and 5\% asphalt, overlain by a $152-\mathrm{mm}$ - (6-in.-) thick asphalt pavement, were up to $70 \%$ higher than the vertical stress predicted by Boussinesq and higher than that in other types of base-many of which had lower vertical stresses than those predicted by Boussinesq. Thus, more effort should focus on accurately modeling stress distribution through the various aggregates that the military may use, indeed may be forced to use, in constructing geotextile-reinforced unsurfaced roads.

\section{CONCLUSION}

For all wheeled U.S. military vehicles, the wheel load may safely and accurately be assumed to be circular if the aggregate that is loaded can be modeled as a linearly elastic material (e.g., compacted, crushed rock). Because the U.S. Army design procedure to use geotextiles overlain with high-quality aggregate to stabilize low-bearing-capacity soil for trafficking with wheeled vehicles (U.S. Army and U.S. Air Force 1995) assumes that the wheel load applied at the surface is in the shape of a circle, no changes are required in this approach to modeling wheel loads. However, if a vehicle does produce loads than can be approximated as uniformly loaded rectangles with length/width ratios of about 4 or greater, (e.g., tracked vehicles) this ques-

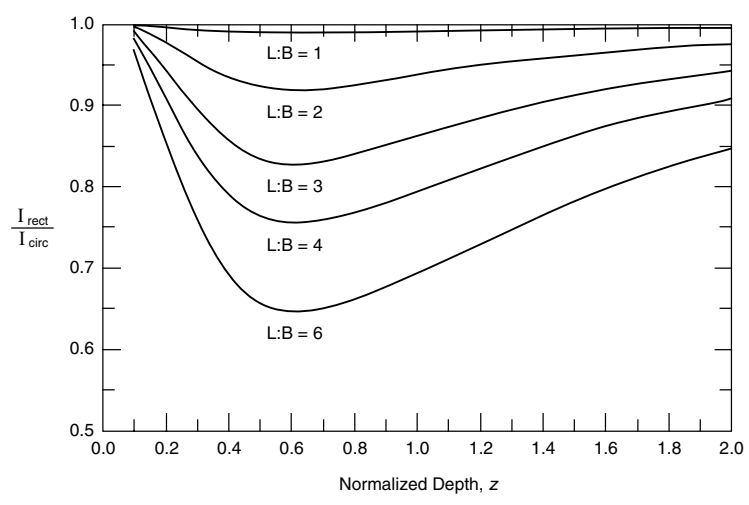

Figure 5. Ratio of the reduction in applied stress with depth for a unit rectangle to a unit circle for various length/width $(L: B)$ ratios of the rectangle. 
tion should be reconsidered in order to save aggregate material. Furthermore, the Mathcad spreadsheet as shown in Appendix A can be used to calculate the stress reduction at depth below the rectangular loads.

More important than wheel load shape is whether the aggregate that is placed on top of the geotextile can be accurately modeled as a linearly elastic material, and, therefore, whether the vertical stresses are reasonably approximated by the Boussinesq method (as the current design method assumes). Indeed, stress concentrations in sand and in clay soil compared to Boussinesq predictions have been noted. Thus, if low quality aggregate composed of rounded gravel, containing sand or fines, or both, must be used in geotextile reinforcement of low-bearing-capacity soil, this question should be addressed.

\section{LITERATURE CITED}

Barenberg, E.J., J. Hales, and J. Dowland (1975) Evaluation of soil-aggregate systems with MIRAFI fabric. University of Illinois Report No. UILU-ENG75-2020, prepared for Celanese Fibers Marketing Company.

Bowles, J.E. (1988) Foundation Analysis and Design, 4th edition. New York: McGraw-Hill, Inc.

Henry, K.S. (1999) Geotextiles to stabilize unsurfaced roads on thawing, low-bearing capacity soils: A comparison of two design methods for use by the U.S. Army. U.S. Army Cold Regions Research and Engineering Laboratory, Special Report 99-7.
Herner, R.C. (1955) Effect of base course quality on load transmission through flexible pavement. In Proceedings, Highway Research Board, p. 224-233.

Mathsoft (1998) Mathcad 8 Professional. Cambridge, Massachusetts: MathSoft Inc.

McMahon, T.F., and E.J. Yoder (1960) Design of a pressure-sensitive cell and model studies of pressure in a flexible pavement subgrade. In Proceedings, Highway Research Board, 39th Annual Meeting, National Academy of Sciences-National Research Council, Washington, D.C., p. 650-682.

Newmark, N.M. (1935) Simplified computation of vertical pressures in elastic foundations. University of Illinois Bulletin, 33(4).

Newmark, N.M. (1942) Influence charts for computation of stresses in elastic foundations. University of Illinois Bulletin, 40(12).

Sowers, G.F., and A.B. Vesic (1962) Vertical stresses in subgrades beneath statically loaded flexible pavements. In Stress Distribution in Earth Masses. Highway Research Board Bulletin 342, NAS-NRC, Washington, DC, p. 90-120.

U.S. Army TACOM (1999) http://www.tacom.army. $\mathrm{mil} / \mathrm{dsa} / \mathrm{pm} \_$htv/programs.html.

U.S. Army and U.S. Air Force (1995) Engineering use of geotextiles. TM5-818-8/AFJMAN 32-1030, Headquarters, Departments of the Army and the Air Force, Washington, D.C.

Yoder, E.J., and M.W. Witczak (1975) Principles of Pavement Design, 2nd edition. New York: John Wiley and Sons. 


\section{APPENDIX A: ANALYTICAL STUDY OF MAXIMUM VERTICAL STRESSES UNDER UNIFORMLY LOADED RECTANGLES AND CIRCLES}

This worksheet, nrmlshapestudymatrix.mcd, prepared by Karen S. Henry of The U.S. Army Cold Regions Research and Engineering Laboratory, Hanover, NH, compares the distributions of vertical stress at depth of uniformly loaded circles and rectangles by the respective Boussinesq equations. F can be varied to study the influence of the length/width ratio. $z$ may also be varied to determine the stress at various depths.

$$
\text { Assume unit Areas: } \quad \text { Area }:=1 \quad r:=\sqrt{\frac{\text { Area }}{\pi}} \quad r=0.564 \quad F:=6
$$

$F$ is the ratio of the length, $L$ to the width, $B$ of the rectangle unit area. Note that $z$ is a vector.

$$
\begin{aligned}
& \mathrm{i}:=0 . .19 \\
& \mathrm{~B}(\mathrm{~F}):=\sqrt{\frac{\text { Area }}{\mathrm{F}}} \quad \mathrm{L}(\mathrm{F}):=\mathrm{F} \cdot \mathrm{B}(\mathrm{F}) \quad \mathrm{z}_{\mathrm{i}}:=\frac{\mathrm{i}}{10}+0.1 \quad \mathrm{~L}(\mathrm{~F}) \cdot \mathrm{B}(\mathrm{F})=1
\end{aligned}
$$

Divide the rectangle into four sections:
$X(F):=\frac{L(F)}{2}$
$\mathrm{Y}(\mathrm{F}):=\frac{\mathrm{B}(\mathrm{F})}{2}$
$\mathrm{X}(\mathrm{F})=1.225$
$Y(F)=0.204$

Define $V$ and $A$ for use in Newmark's rectangle equation.

$$
V(z, F):=\sqrt{\frac{X(F)^{2}+Y(F)^{2}+z^{2}}{z^{2}}} \quad A(z, F):=\frac{X(F) \cdot Y(F)}{z^{2}}
$$

This expression, of the fraction of the applied load at $z$, is for the sum of four rectangles of dimension $X$ by $Y$.

$$
\begin{aligned}
& \operatorname{Irect} 1(\mathrm{z}, \mathrm{F}):=\frac{1}{\pi} \cdot\left[\left(\frac{2 \cdot A(\mathrm{z}, \mathrm{F}) \cdot \mathrm{V}(\mathrm{z}, \mathrm{F})}{\mathrm{V}(\mathrm{z}, \mathrm{F})^{2}+\mathrm{A}(\mathrm{z}, \mathrm{F})^{2}} \cdot \frac{\mathrm{V}(\mathrm{z}, \mathrm{F})^{2}+1}{\mathrm{~V}(\mathrm{z}, \mathrm{F})^{2}}\right)+\operatorname{atan}\left(\frac{2 \cdot A(\mathrm{z}, \mathrm{F}) \cdot \mathrm{V}(\mathrm{z}, \mathrm{F})}{\mathrm{V}(\mathrm{z}, \mathrm{F})^{2}-\mathrm{A}(\mathrm{z}, \mathrm{F})^{2}}\right)\right] \\
& \operatorname{Irect} 2(\mathrm{z}, \mathrm{F}):=\frac{1}{\pi} \cdot\left[\left(\frac{2 \cdot \mathrm{A}(\mathrm{z}, \mathrm{F}) \cdot \mathrm{V}(\mathrm{z}, \mathrm{F})}{\mathrm{V}(\mathrm{z}, \mathrm{F})^{2}+\mathrm{A}(\mathrm{z}, \mathrm{F})^{2}} \cdot \frac{\mathrm{V}(\mathrm{z}, \mathrm{F})^{2}+1}{\mathrm{~V}(\mathrm{z}, \mathrm{F})^{2}}\right)+\operatorname{atan}\left(\frac{2 \cdot \mathrm{A}(\mathrm{z}, \mathrm{F}) \cdot \mathrm{V}(\mathrm{z}, \mathrm{F})}{\mathrm{V}(\mathrm{z}, \mathrm{F})^{2}-\mathrm{A}(\mathrm{z}, \mathrm{F})^{2}}\right)+\pi\right] \\
& \operatorname{Irect}(z, F):=\operatorname{if}(A(z, F)>V(z, F), \operatorname{Irect} 2(z, F), \operatorname{Irect} 1(z, F)) \\
& \operatorname{Icirc}(z):=\left[1-\left(\cos \left(\operatorname{atan}\left(\frac{r}{z}\right)\right)\right)^{3}\right]
\end{aligned}
$$


Results:

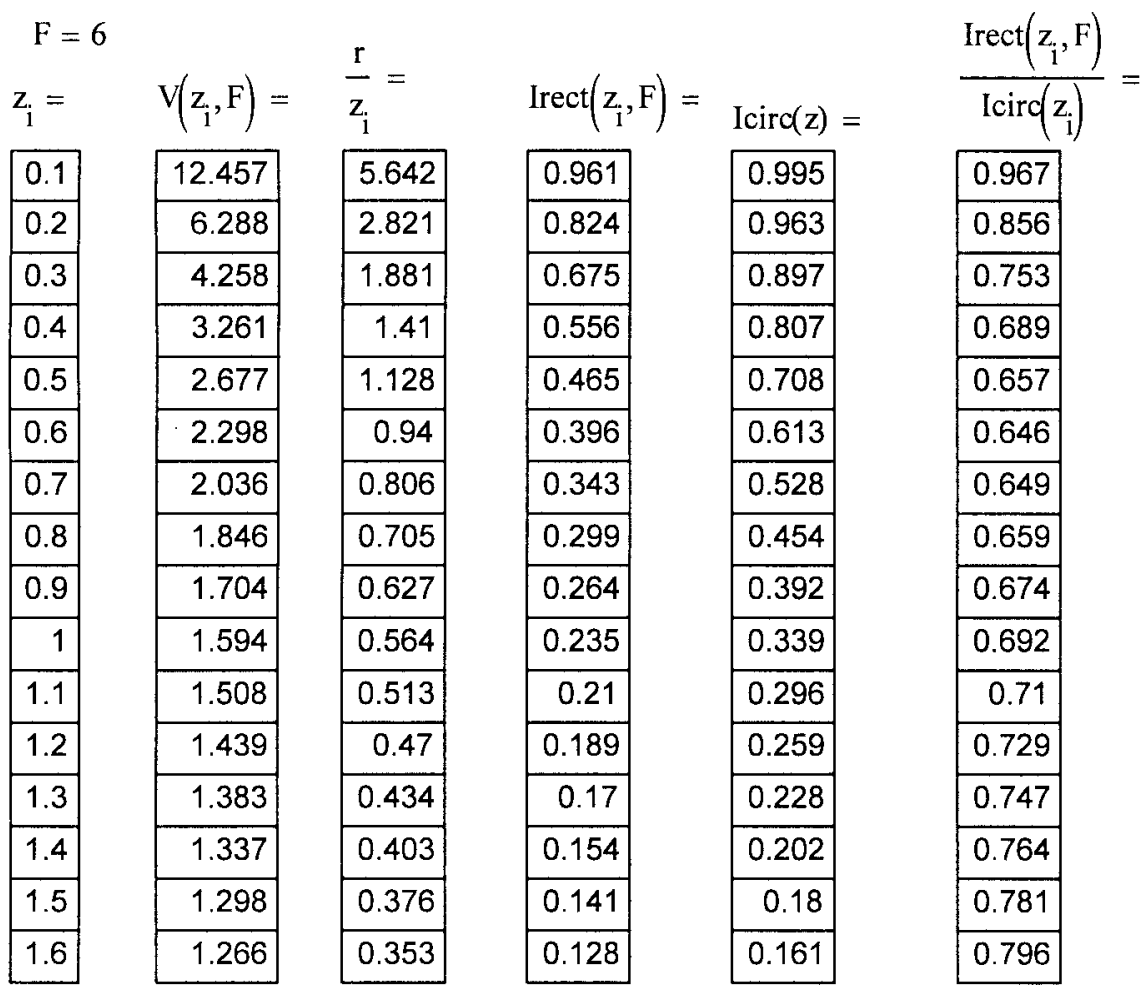

Note that the augment function pastes matrices next to each other. The arrays generated by the computations that were not already vectors have to first be "vectorized with the vectorize function ( $z$ and functions of $z$ are vectors, but not functions containing both $z$ and $F$ ). This is done so that all elements in the matrix generated by the results can be exported to a spreadsheet.

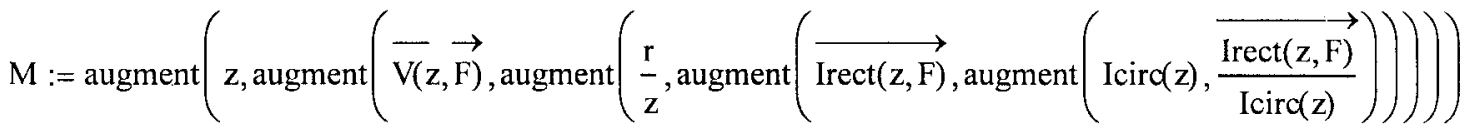

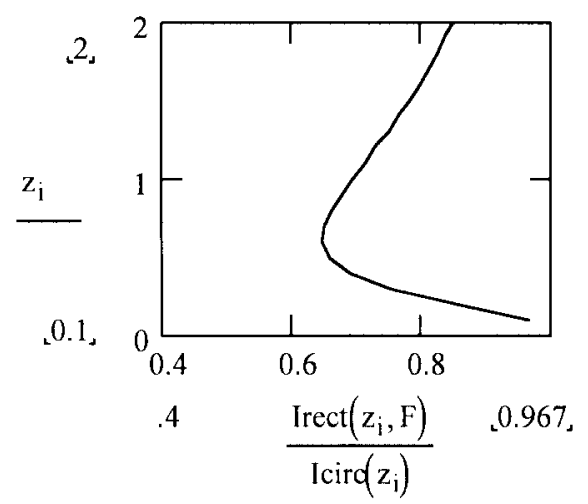




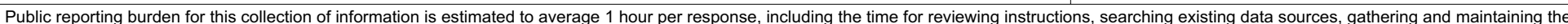

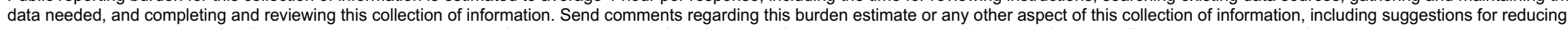

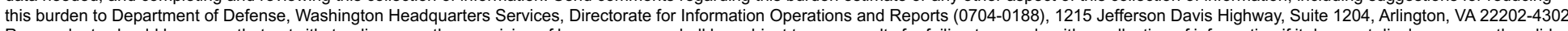

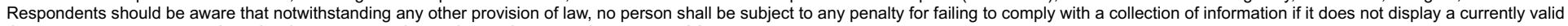
OMB control number. PLEASE DO NOT RETURN YOUR FORM TO THE ABOVE ADDRESS.

\begin{tabular}{l|l|}
\hline $\begin{array}{l}\text { 1. REPORT DATE }(D D-M M-Y Y) \\
\text { March } 2001\end{array}$ & $\begin{array}{l}\text { 2. REPORT TYPE } \\
\text { Technical Report }\end{array}$ \\
\hline 4. TITLE AND SUBTITLE & \\
$\begin{array}{l}\text { Influence of Wheel Load Shape on Vertical Stress Reaching Subgrade through an Aggregate } \\
\text { Layer }\end{array}$
\end{tabular}
Layer

3. DATES COVERED (From - To)

5a. CONTRACT NUMBER

5b. GRANT NUMBER

5c. PROGRAM ELEMENT NUMBER

6. AUTHOR(S)

5d. PROJECT NUMBER

Karen S. Henry

5e. TASK NUMBER

5f. WORK UNIT NUMBER

7. PERFORMING ORGANIZATION NAME(S) AND ADDRESS(ES)

8. PERFORMING ORGANIZATION REPORT NUMBER

U.S. Army Engineer Research and Development Center

Cold Regions Research and Engineering Laboratory

72 Lyme Road

ERDC/CRREL TR-01-8

Hanover, New Hampshire 03755-1290

9. SPONSORING/MONITORING AGENCY NAME(S) AND ADDRESS(ES)

10. SPONSOR / MONITOR'S ACRONYM(S)

Office of the Chief of Engineers

Washington, DC

11. SPONSOR / MONITOR'S REPORT NUMBER(S)

\section{DISTRIBUTION / AVAILABILITY STATEMENT}

Approved for public release; distribution is unlimited.

Available from NTIS, Springfield, Virginia 22161.

13. SUPPLEMENTARY NOTES

\section{ABSTRACT}

The U.S. Army design procedure to stabilize low-bearing-capacity soil with geotextiles is based on the assumption that the applied surface load (the wheel load) is in the shape of a circle. The maximum vertical stress that reaches the subgrade through overlying aggregate is then estimated on the basis of the assumption that the aggregate is an elastic, homogeneous, isotropic half-space and, therefore, that the stress distribution can be estimated by using the Boussinesq method. To study the extent to which the shape of the applied load influences the stress that reaches the subgrade through the aggregate layer, the maximum vertical stress at depth predicted by the Boussinesq method was computed and compared for circular and rectangular loads. A comparison of the maximum vertical stress beneath circular and rectangular loads as a function of depth indicated that the differences were insufficient to warrant a change in the design procedure for rectangular load geometries that have length/width ratios of 3 or less, and, furthermore, that assuming that the load is circular is conservative. For length/ width ratios of 3 or less, the maximum vertical stress applied by a rectangle is at least $85 \%$ of that applied by a circle.

15. SUBJECT TERMS

Boussinesq Wheel load

Stress distribution

\begin{tabular}{|c|c|c|c|c|c|}
\hline \multicolumn{3}{|c|}{ 16. SECURITY CLASSIFICATION OF: } & \multirow{2}{*}{$\begin{array}{l}\text { 17. LIMITATION OF } \\
\text { OF ABSTRACT }\end{array}$} & \multirow{2}{*}{$\begin{array}{l}\text { 18. NUMBER } \\
\text { OF PAGES }\end{array}$} & 19a. NAME OF RESPONSIBLE PERSON \\
\hline a. REPORT & b. ABSTRACT & c. THIS PAGE & & & 19b. TELEPHONE NUMBER (include area code) \\
\hline $\mathrm{U}$ & $\mathrm{U}$ & $\mathrm{U}$ & $\mathrm{U}$ & 13 & \\
\hline
\end{tabular}

